\title{
Hyperactivity and Sensitization to Psychostimulants following Cholera Toxin Infusion into the Nucleus Accumbens
}

\author{
S. Tiffany Cunningham and Ann E. Kelley \\ Department of Psychology, Northeastern University, Boston, Massachusetts 02115
}

\begin{abstract}
Although manipulation of second messenger systems is widespread in cell biology, there are few experiments examining the consequences of such manipulation on behavior. In three separate experiments, we extended earlier work by Miller and Kelly (1975) that examined the behavioral effects of microinfusion of cholera toxin (CTX) into the nucleus accumbens ( $N$. Acc.) in rats. CTX is a bacterial toxin that ADP ribosylates the $G_{\text {, }}$ transducer protein and stimulates production of CAMP. For Experiment $I$, three groups of rats received either saline or CTX (50 or $500 \mathrm{ng} / \mu \mathrm{l}$ ) into the $\mathrm{N}$. Acc. Locomotor activity was measured for $4 \mathrm{hr}$ following a single CTX infusion and subsequently for 4 hr on 6 consecutive days. No acute effects on motor activity were observed. However, the $\mathbf{5 0 0} \mathrm{ng}$ dose of CTX induced long-lasting hyperactivity that was apparent $24 \mathrm{hr}$ later and that lasted $4 \mathrm{~d}$. A smaller but significant hypermotility occurred on days 4 and 5 following infusion of the $\mathbf{5 0} \mathrm{ng}$ dose. Site specificity of this effect was investigated in Experiment II by infusion of CTX (250 $\mathrm{ng} / \mu \mathrm{l})$ into either the N. Acc. or the posterior dorsal striatum (PDS). CTX treatment of the PDS had no behavioral effects while the long-lasting hyperactivity following treatment of the $\mathbf{N}$. Acc. was replicated. In Experiment III the effect of intra-accumbens pretreatment with saline or CTX (10 ng/ $\mu \mathrm{l})$ on $\alpha$-amphetamine $(0.5 \mathrm{mg} / \mathrm{kg}$, i.p.)- and cocaine ( $7 \mathrm{mg} / \mathrm{kg}$, i.p.)-induced motor activity was investigated. This low dose of CTX did not increase baseline motor activity 1 d later; however, rats previously treated with CTX showed a sensitized locomotor response to amphetamine and cocaine but not saline challenges. These data suggest that

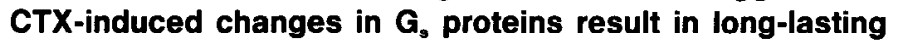
upregulation of the CAMP system. This upregulation is reflected by enhanced motor responses normally mediated by the $N$. Acc. The results may have important implications for mechanisms underlying drug-induced sensitization and may also have potential as an animal model of mania.
\end{abstract}

[Key words: cholera toxin, amphetamine, cocaine, locomotor activity, nucleus accumbens, sensitization]

\footnotetext{
Received June 8, 1992; revised Dec. 1, 1992; accepted Dec. 7, 1992.

This research was supported by Grant DA04788 from the National Institute on Drug Abuse (A.E.K.). S.T.C. was supported by the American Psychological Association/Minority Fellowship Program (NIMH).

Correspondence should be addressed to S. Tiffany Cunningham, Northeastern University, Department of Psychology, 125 Nightingale Hall, Boston, MA 02115. Copyright $(C) 1993$ Society for Neuroscience $0270-6474 / 93 / 132342-09 \$ 05.00 / 0$
}

Over the past decade there have been considerable advances in the understanding of neurotransmitter-mediated signal transduction mechanisms. It is well established that dopamine receptors are linked to the cAMP second messenger system via membrane-bound G-proteins (Stoof and Kcbabian, 1981; Fujita et al., 1985). The dopamine $D_{1}$ receptor is coupled to a stimulatory $G$-protein $\left(G_{s}\right)$, which when activated increases production of adenylate cyclase and cAMP. Stimulation of the dopamine $\mathrm{D}_{2}$ receptor leads to inhibition of adenylate cyclase through activation of an inhibitory $G$-protein $\left(G_{i}\right)$. The striatum, which is the main target of the midbrain dopaminergic neurons, contains among the highest levels of adenylate cyclase in the brain (Worley et al., 1986).

Although there is a substantial amount of information concerning the interactions between dopamine and the cAMP system at the cellular level, little is known about the relationship between signal transduction mechanisms and behavior. In neurochemical experiments, researchers have utilized two bacterial toxins, pertussis toxin (PTX) and cholera toxin (CTX), to manipulate the cAMP system. PTX ADP-ribosylates a subunit of the $G_{1}$-protein uncoupling the protein from the $D_{2}$ reccptor and impairing inhibition of adenylate cyclase (Murayama and $\mathrm{Ui}$, 1983; Fujita et al., 1985; Olianas and Onali, 1987). CTX prevents the inactivation of the $G_{s}$ protein, thus inducing continual production of cAMP (Gill and Meren, 1978). Although these compounds have been used extensively in cell biology, there are relatively few experiments investigating the behavioral effects of local brain injections of these substances. One notable exception is an early study by Miller and Kelly (1975) that investigated the behavioral effects of CTX infusion in the nucleus accumbens (N. Acc.; Miller and Kelly, 1975). In that article it was reported that CTX infusion induced a delayed long-lasting increase in motor activity. More recently it has been reported that injection of PTX into the ventral tegmental area site of the A10 dopamine cell bodies augments the locomotor response to cocaine $14 \mathrm{~d}$ later (Steketee and Kalivas, 1991). These authors suggest that alterations in second messenger systems may underlie the long-term effects of drugs such as opiate and cocaine, a theory for which there is biochemical evidence (Terwilliger et al., 1991). There are also several studies demonstrating reduction of apomorphine-induced effects following PTX injection into striatum (Fujita et al., 1985; Kelly et al., 1987). Thus, some evidence exists suggesting that manipulations of second messenger systems can result in altcrations in behavior.

The present experiments further examined the behavioral effects of intra-accumbens CTX reported by Miller and Kelly (1975). The dose-response profile and the site specificity of the 
behavioral effect were investigated. In addition, the influence of this treatment on the locomotor response to psychostimulants was evaluated.

The N. Acc., a major forebrain target of the mesolimbic dopamine system, is widely recognized to be involved in motor aroisal reward and locomotor activation (Fibiger and Phillips, 1986). For example, lesion of the dopamine neurons in this region prevents the activating and reinforcing effects of psychostimulants such as cocaine and amphetamine (Roberts et al., 1980; Koob and Bloom, 1988) and intra-accumbens injection of such compounds enhances locomotor activity (Pijnenburg et al., 1976; Delfs et al., 1990). Therefore, for the initial studies of second messenger manipulations, the N. Acc. was the target site.

\section{Materials and Methods}

\section{Animals and surgery}

Male Sprague-Dawley rats $(N=52)$ (Charles River Breeding Laboratories, Wilmington, MA) were used for these experiments. Upon arrival, animals were handled by experimenter and housed in pairs in clear plastic cages with wire grid floors. Food and water were available ad libitum. Animals were housed on a $12 \mathrm{hr}$ light/12 hr dark cycle with lights on at 0700 and off at 1900 .

For surgery, animals were anesthetized with Nembutal $(50 \mathrm{mg} / \mathrm{kg}$, i.p.) and given atropine $(0.54 \mathrm{mg} / \mathrm{kg}, 0.1 \mathrm{cc}$, s.c). Standard stereotaxic procedures were used to implant stainless steel ( 23 gauge) cannula guides bilaterally. Cannulas were aimed either at the nucleus accumbens or posterior dorsal striatum (PDS) depending on the experiment. Based on the atlas of Pellegrino and Cushman (1967), coordinates for the nucleus accumbens ( $\mathrm{N}$. Acc.) were (in $\mathrm{mm}$ ) anteroposterior (A-P) +3.5 from bregma, lateromedial (L-M) \pm 1.7 from midline, dorsoventral (D-V) -5.7 from skull surface. For the PDS, the coordinates were A-P +1.6 , $\mathrm{L}-\mathrm{M} \pm 3.0, \mathrm{D}-\mathrm{V}-4.0$. A light-curable dental resin and liquid acrylic were used to affix the cannulas to skull screws. Stainless steel wire stylets were placed in the cannulas to prevent occlusion. Animals were given a 2-3 d recovery period before the onset of behavioral testing.

\section{Drugs and microinfusion}

Cholera toxin (CTX; Sigma Chemical Company, St. Louis, MO) was dissolved in isotonic $(0.9 \%)$ saline for brain injections. $d$-Amphetamine sulfate and cocaine hydrochloride (Sigma) were also dissolved in $0.9 \%$ saline for intraperitoneal (i.p.) injections. For microinjections, animals were lightly restrained by the experimenter, the wire stylets were removed, and cannula guides were cleared with precut square dental broaches. Bilateral microinjector cannulas (30 gauge), attached via polyethylene tubing (P-E 10, Clay Adams) to a microdrive pump (Harvard Apparatus), were lowered through the guide cannulas and infusions were administered at a rate of $0.5 \mu \mathrm{l} / \mathrm{min}$. The volume of all intracerebral infusions was $1 \mu \mathrm{l}$ in order to maximize spread throughout the nucleus accumbens (a preliminary study showed smaller effects with a $0.5 \mu \mathrm{l}$ volume). Total microinjection time was $2 \mathrm{~min}$ followed by a diffusion period of $1 \mathrm{~min}$. Subsequently, injector cannulas were removed, the stylets replaced, and the animal placed in the activity cages. All animals were given a preliminary saline infusion to adapt them to the procedure before the experimental testing.

\section{Behavioral apparatus}

Fifteen clear plastic cages equipped with photocells and wire grid floors were used to measure spontaneous motor activity. A total of six infrared photocells surrounded each cage; two were situated along the horizontal axis to record horizontal activity, and four were placed at the top of the cage to record vertical activity (rearing). The photocells were interfaced to a microprocessor (Stimtek, Arlington, MA), and the total number of photobeam breaks (counts) was recorded every $10 \mathrm{~min}$ for a total of $240 \mathrm{~min}$. Prior to surgery, animals were habituated to the activity cages for $4 \mathrm{hr}$. Animals were always tested between 0730 and 1230 . On test days, rats were habituated to activity cages for a minimum of $2 \mathrm{hr}$ before drug infusion.

\section{Experiments}

Three experiments were carried out.

Experiment I. CTX $(0,50,500 \mathrm{ng} / 1 \mu \mathrm{l})$ was infused into the nucleus accumbens in 18 animals. There were three groups of six rats for each dose. A single infusion was given on day 1 of behavioral testing. Animals were placed immediately into the activity cages following CTX infusion and motor activity was measured for $4 \mathrm{hr}$. Motor behavior was also recorded for $4 \mathrm{hr}$ each day for the duration of $6 \mathrm{~d}$ following the single CTX infusion.

Experiment $I I$. In this expcriment an intcrmediate dosc $(250 \mathrm{ng} / 1 \mu \mathrm{l})$ of CTX was used and the site specificity of the behavioral effect was tested. CTX was infused into the nucleus accumbens $(N=6)$ and the posterior dorsal striatum $(N=6)$ of rats. Locomotor activity was measured for $4 \mathrm{hr}$ following microinjection on day 1 and for 5 consecutive days.

Experiment III. For amphetamine tests two groups of rats with $\mathrm{N}$. Acc. cannulation were used. The saline group was a newly operated group that had never received injections $(N=6)$. The CTX group consisted of the rats from Experiment II, which had received one infusion of CTX (250 ng) $9 \mathrm{~d}$ earlier $(N=6)$. The saline group received an intra-accumbens infusion of saline and the CTX group received an intra-accumbens infusion of CTX $(10 \mathrm{ng} / \mu \mathrm{l})$. Following infusion animals were placed in activity cages for $4 \mathrm{hr}$. On the next day, rats were habituated to the apparatus for $90 \mathrm{~min}$ and then administered $d$-amphctamine $(0.5 \mathrm{mg} / \mathrm{kg}$, i.p.) and returned to the testing cages for $150 \mathrm{~min}$.

For cocaine tests, two new groups of rats were used ( $N=8$ /group). The animals in each group received either saline or CTX infusion into N. Acc. $(10 \mathrm{ng} / \mu \mathrm{l})$ with identical testing procedures as described above for the infusion day. On the next day (following a $90 \mathrm{~min}$ habituation), animals were given cocaine $(7.0 \mathrm{mg} / \mathrm{kg}$, i.p.) and placed into activity cages for an additional $150 \mathrm{~min}$. Five days after the cocaine tests animals were given another CTX or saline intra-accumbens infusion (pretreatment groups held constant). Twenty-four hours later, animals were given a systemic saline challenge and placed in the activity cages.

\section{Data analysis}

An IBM-compatible statistical software package (Crunch Interactive Statistical Package, CRISP) was used for overall analysis of variance (ANOVA). A two-factor design was used with a between-factor (group) and a within-factor (time). Post hoc comparisons (Newman-Keuls) were subsequently carried out to ascertain pairwise differences between means. Analysis of simple main effects for interactions was also conducted (Bruning and Kintz, 1987).

\section{Histology}

At the termination of the experiments, animals were given an overdose of Nembutal and were perfused transcardially with $0.9 \%$ saline followed by $10 \%$ formalin. Brains were removed and stored in $10 \%$ formalin for a minimum of $3 \mathrm{~d}$. Coronal sections $(60 \mu \mathrm{m})$ were obtained and mounted on slides for cresyl violet staining. All injection tip locations were visualized and verified for striatal placements.

\section{Results}

\section{Experiment I. Effects of CTX infusion into the N. Acc. on locomotor activity}

Acute administration (day 1) of CTX into the N. Acc. had no effect on locomotor activity or rearing (Fig. 1A). (Scores for rearing are nol shown, as they followed a similar pattern to locomotor activity throughout the experiments.) It can be observed from Figure $1 A$ that the activity levels for all groups were similar. In contrast, in the group that had received the high dose of CTX there was a marked enhancement of motor activity 24 hr later (day 2). An overall ANOVA revealed a significant between-groups effect $[F(2,16)=13.15, P<0.001]$ on day 2 . Post hoc analysis indicated that this effect was due to the $500 \mathrm{ng}$ dose relative to saline (Newman-Keuls, $P<0.01$ ). As shown in Figure $1 B$, the animals previously treated with $500 \mathrm{ng}$ of CTX were hyperactive throughout the test session.

On day 3 (Fig. 1C) 2 d postinfusion, a significant betweengroups effect was obtained $[F(2,16)=6.08, P<0.01]$. Further 


\section{A DAY 1}

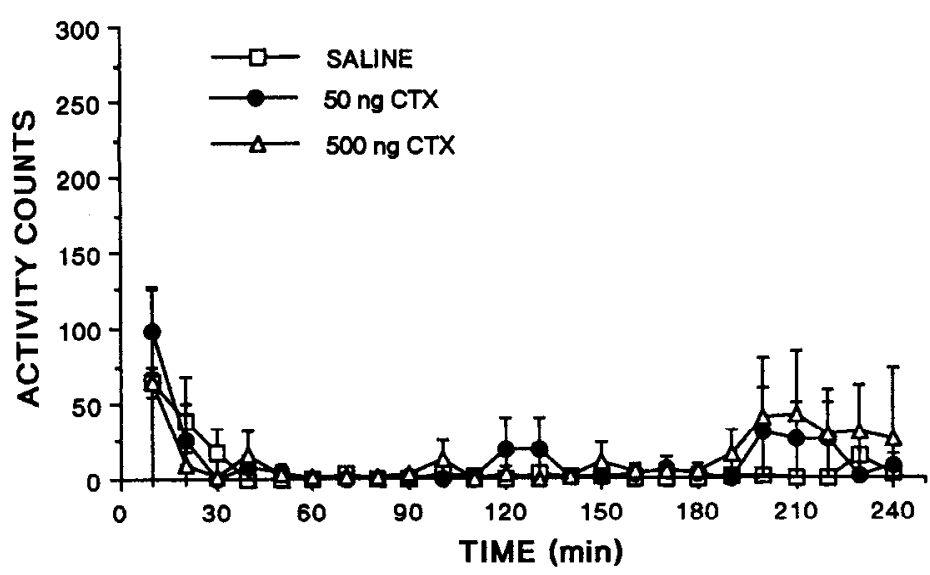

\section{DAY 3}

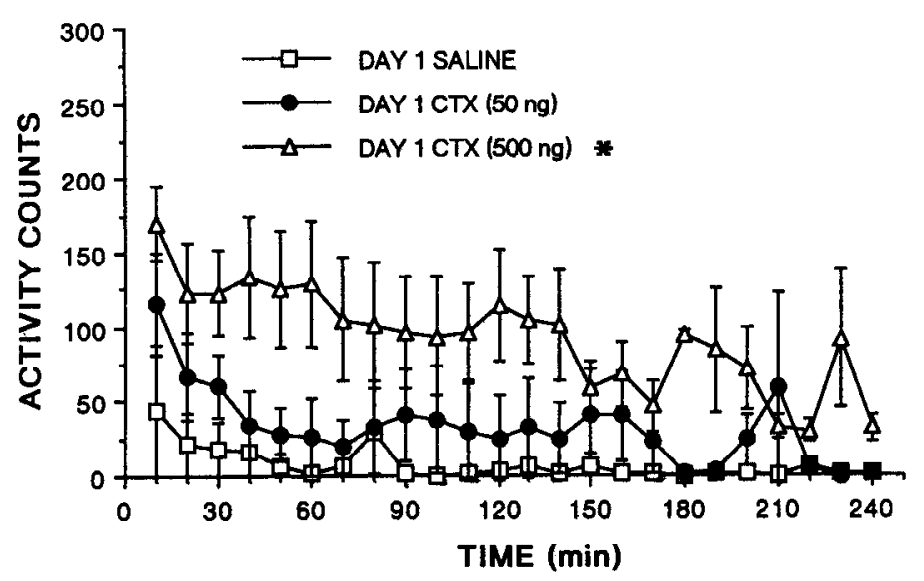

E DAY 5

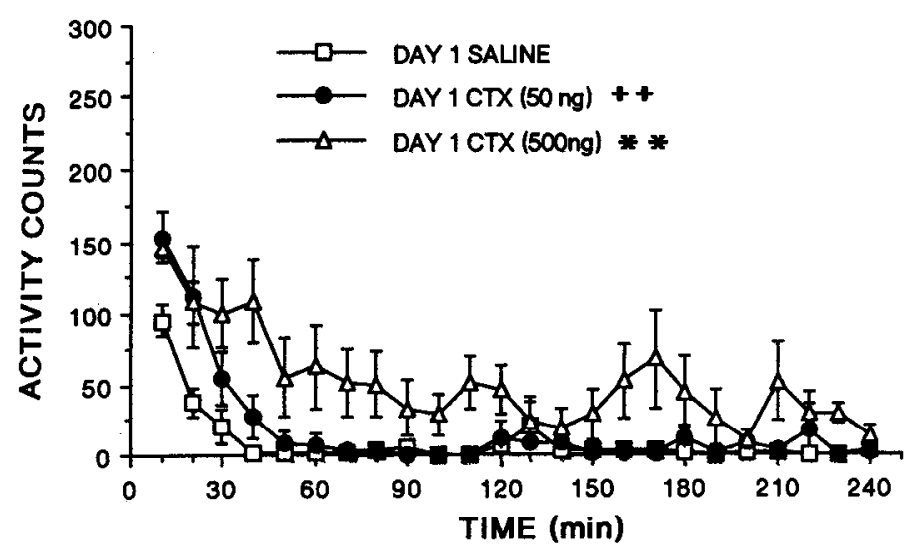

B DAY 2

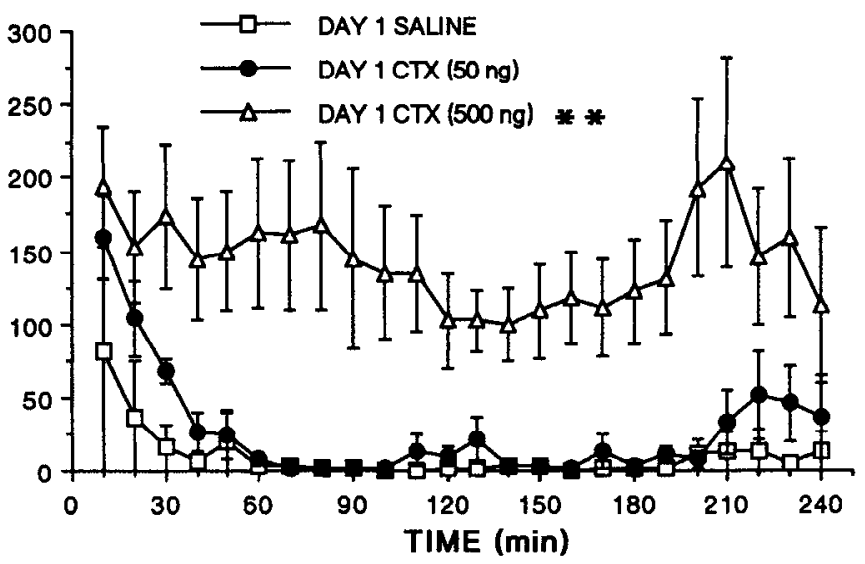

D DAY 4

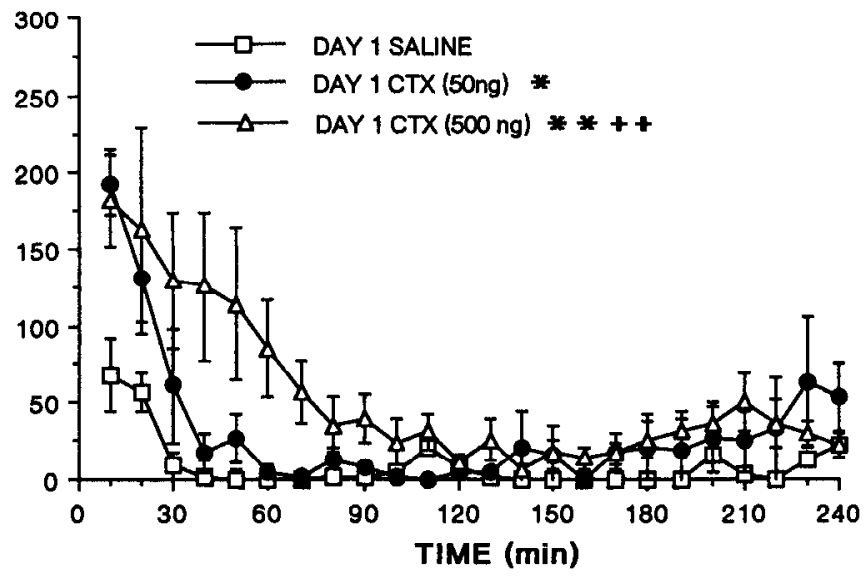

F DAY 6

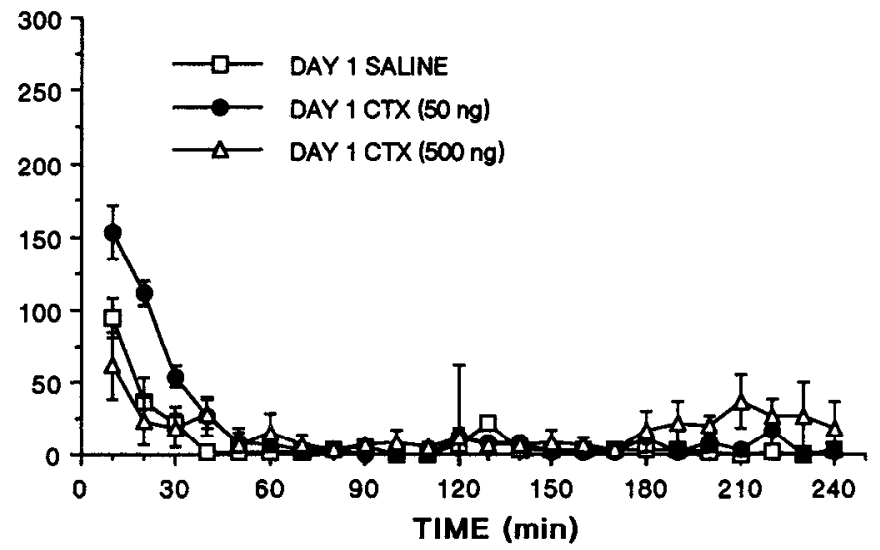

Figure 1. The effects of a single microinjection of CTX (day 1) into N. Acc. ( $N=6$ per group) on motor activity. Graphs represent the pattern of motor activity over a $4 \mathrm{hr}$ period for $6 \mathrm{~d}$. Each symbol is the mean number of counts for that time point \pm the SEM.,$++ P<0.01$ dose $x$ time interaction with respect to saline; ${ }^{*}, P<0.05 ;{ }^{* *}, P<0.01$ dose effect compared to saline.

analysis revealed that the $500 \mathrm{ng}$ dose contributed to this effect (Newman-Kculs, $P<0.05$ ). By day 3 some animals in the highdose group $(N=2)$ began to seize, and on subsequent days other animals $(N=2)$ seized as well. The seizures did not persist and animals had recovered by the next test session. By day 4 both the low-dose and high-dose CTX groups showed elevated motor activity as shown in Figure $1 D$. A significant between-groups effect was found $[F(2,15)=13.73, P<0.001]$ for the $50 \mathrm{ng}$ dose (Newman-Keuls, $P<0.05$ ) and the 500 ng dose (NewmanKeuls, $P<0.01$ ). In addition, there was a significant group $\times$ 


\section{A DAY 1}

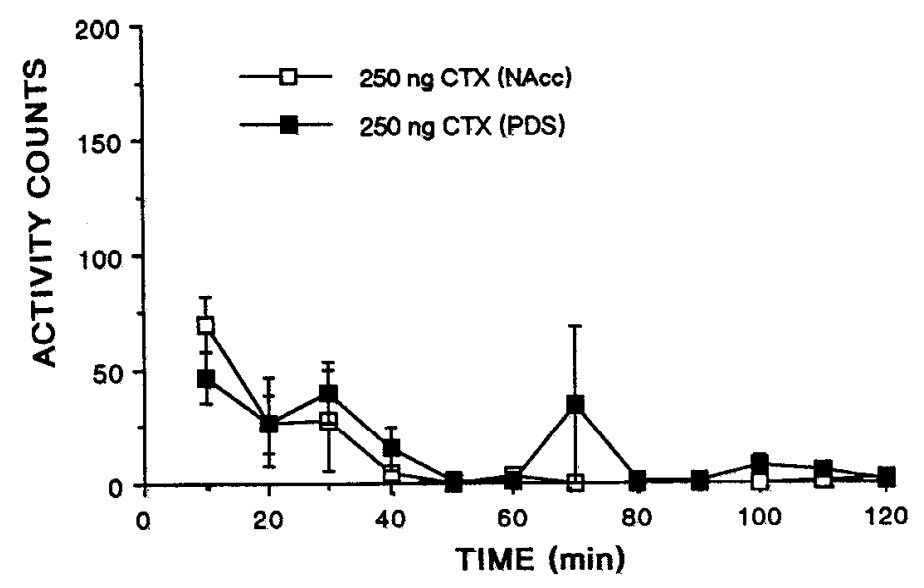

\section{DAY 3}

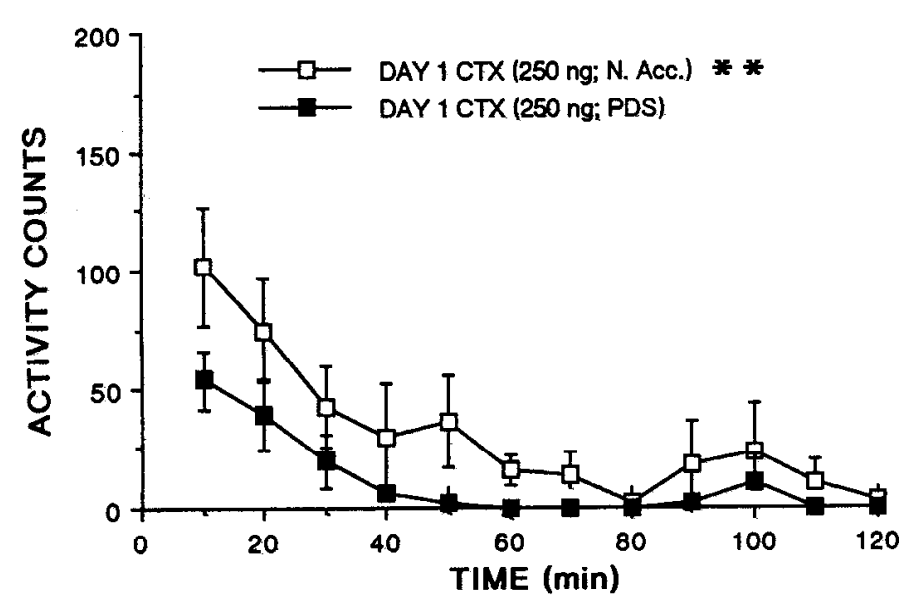

B DAY 2

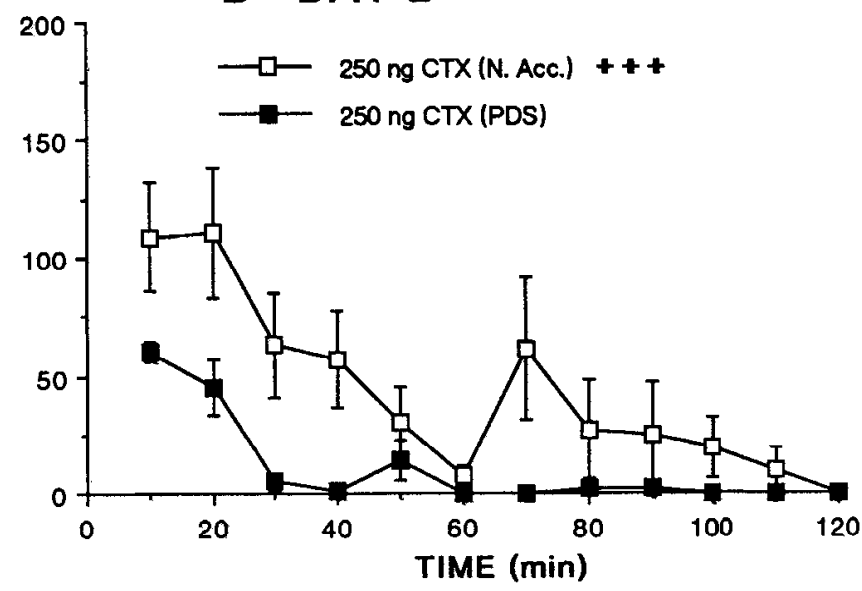

D DAY 4

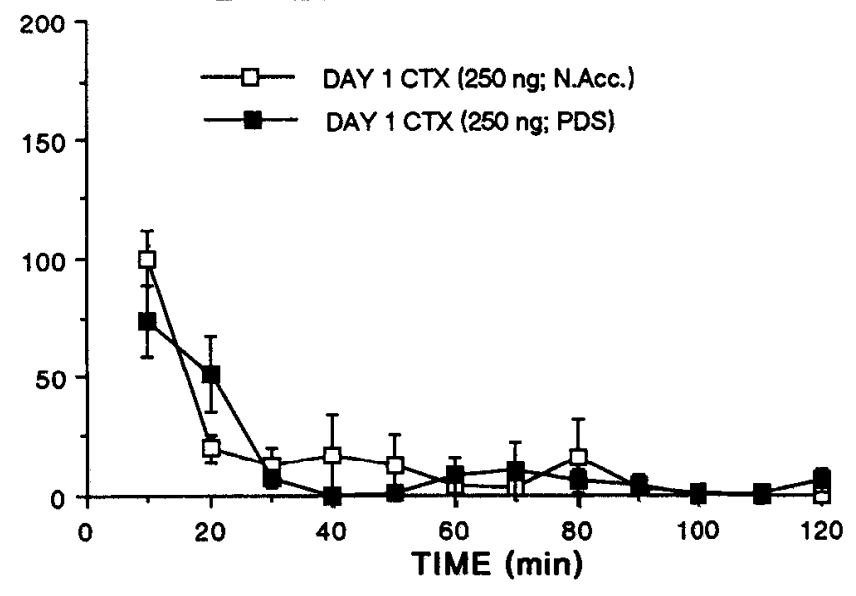

Figure 2. Locomotor activity elicited by one microinfusion of CTX (day 1) into N. Acc. $(N=6)$ or PDS $(N=6)$.,$+++ P<0.001$ treatment site $\times$ time interaction; ${ }^{* *}, P<0.01$ dose effect.

time interaction $[F(46,345)=1.77, P<0.002]$. Analysis of simple main effects indicated this effect to be due to an interaction between the saline group and the $500 \mathrm{ng}$ CTX group $[F(23,345)=2.38, P<0.01]$. As can be observed from Figurc $1 D$, animals in the high-dose group were active for longer periads of time although during the second hour their activity subsided.

Figure $1 E$ illustrates the motor activity in rats on day $5(4 \mathrm{~d}$ postinfusion). An overall group effect was obtained $[F(2,15)=$ $19.28, P<0.001$ ] for the $500 \mathrm{ng}$ dose compared to saline (Newman-Keuls, $P<0.01)$. A group $\times$ time interaction was found $[F(46,345)=1.57, P<0.014]$ to which the $50 \mathrm{ng}$ dose contributed $[F(23,345)=3.36, P<0.01]$. By day 6 all three groups showed similar behavioral profiles with no significant differences as depicted in Figure $1 F$.

Experiment II. Comparison of CTX-induced locomotor effects in the N. Acc. and PDS

Acute infusion of CTX $(250 \mathrm{ng} / \mu \mathrm{l})$ into either the N. Acc. or PDS did not clicit motor activation (Fig. $2 A$ ). Twenty-four hours following infusion, however, the $N$. Acc. group showed elevated activity for the first $100 \mathrm{~min}$ (Fig. $2 B$ ). ANOVA revealed a significant group $\times$ time interaction $[F(23,230)=3.31, P<$
$0.001]$. Figure $2 C$ illustrates the motor activation effects of CTX in the N. Acc. observed on day 3 ( $2 \mathrm{~d}$ postinfusion); a significant group effect was obtained $[F(1,18)=17.78, P<0.002]$. On the subscquent test days, no significant between-group differences were obtained. For all tests, activity in the PDS group was similar to that profile observed in the saline-treated group in experiment $I$.

\section{Experiment III. Effects of CTX pretreatment on psychostimulant-induced locomotor activity}

In all groups of animals, no acute behavioral effects were found following infusion of $10 \mathrm{ng}$ CTX into the N. Acc. Moreover, 24 $\mathrm{hr}$ after this infusion, motor activity in saline- and CTX-treated animals was similar (Fig. 3A, time 0-90 min). However, the group previously treated with CTX showed a potentiation of the motor response to amphetamine (Fig. 3A). The CTX-pretreated group showed a threefold increase in behavioral activation relative to the saline pretreatment group (Fig. $3 B$ ). A significant group $\times$ time interaction was obtained $[F(23,276)=$ 1.73, $P<0.02$ ]. As illustrated in Figure 3, $C$ and $D$, similar results were obtained following cocaine challenge $24 \mathrm{hr}$ after CTX infusion. A greater magnitude of motor activation was 


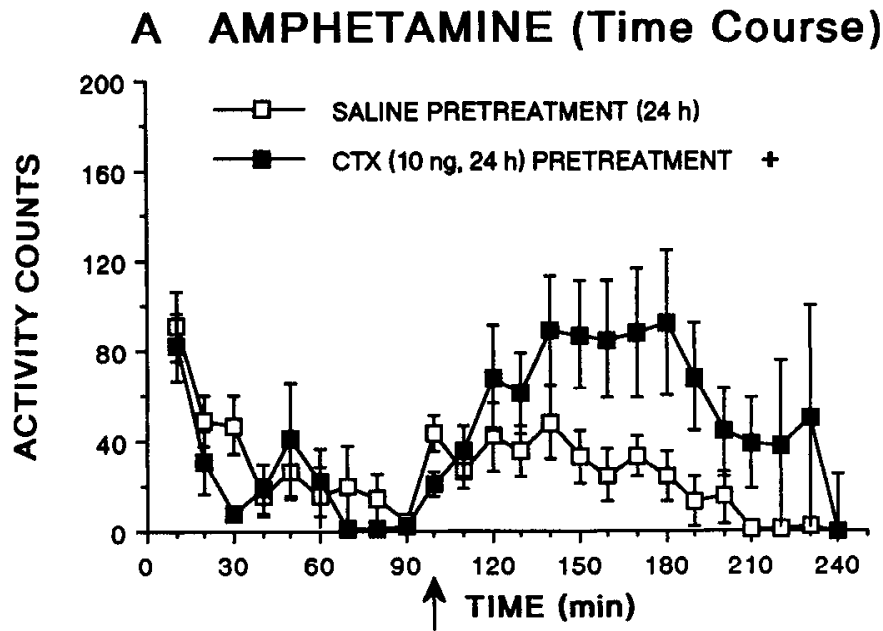

C COCAINE (Time Course)

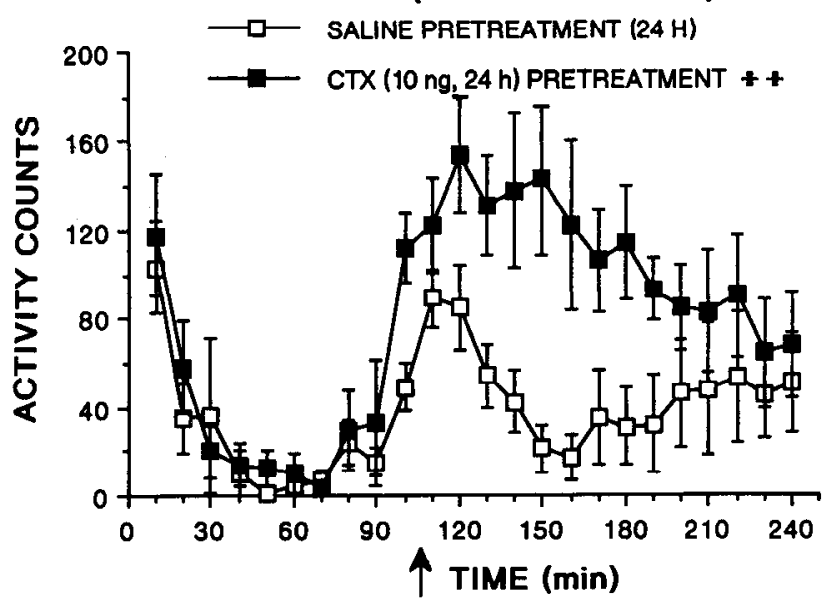

E SALINE (Time Course)

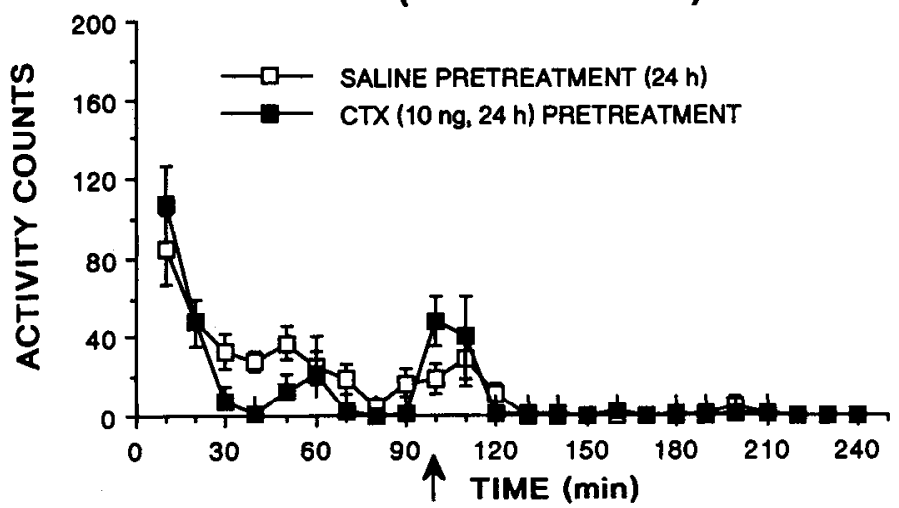

B AMPHETAMINE (Total Activity)

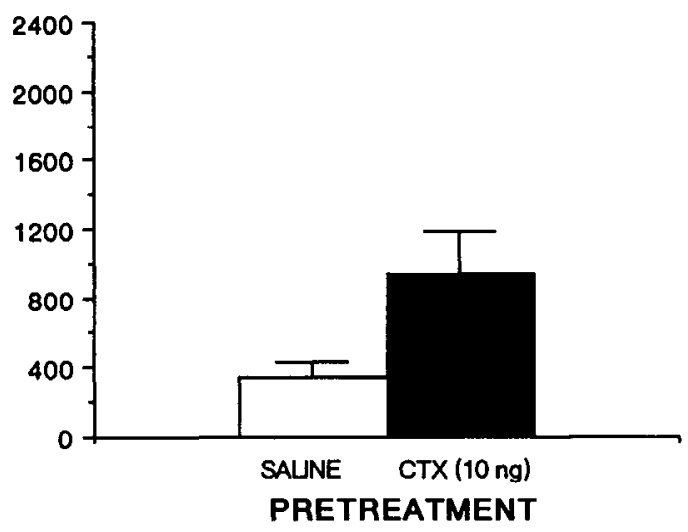

D COCAINE (Total Activity)

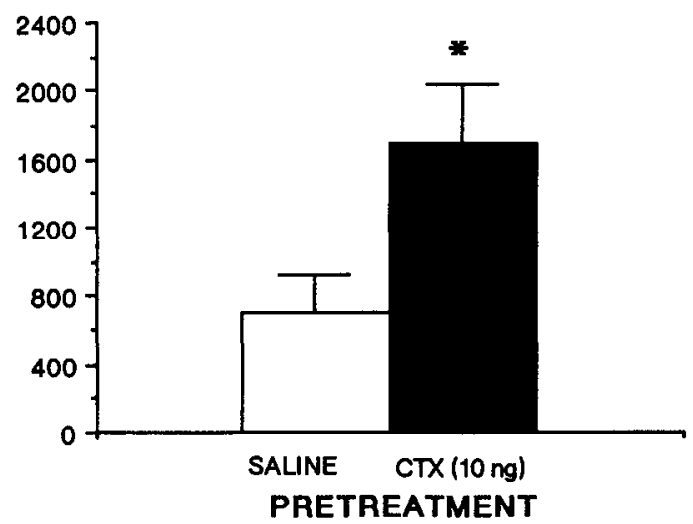

F SALINE (Total Activity)

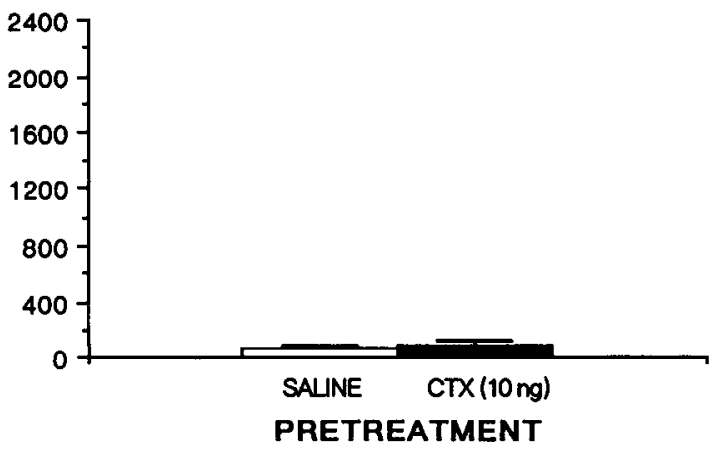

Figure 3. The effects of intra-accumbens CTX ( $10 \mathrm{ng}, 24 \mathrm{hr}$ pretreatment) on psychostimulant-induced locomotor activity. $A$, Time $0-90$ min represents the habituation to the activity cages prior to $d$-amphetamine $(0.5 \mathrm{mg} / \mathrm{kg}$, i.p.) injection (arrow). $B, B a r s$ represent mean of the total activity for the $240 \mathrm{~min}$ test session \pm SEM. $C$, Time course of activity for $90 \mathrm{~min}$ habituation and following cocaine $(7.0 \mathrm{mg} / \mathrm{kg}, \mathrm{i} . \mathrm{p}$.) injection (arrow). D, Mean total activity for saline pretreatment group (open bar) and CTX pretreatment group (solid bar). $E$, Pattern of motor activity 90 min prior to and 140 min following systemic saline injection (arrow). $F$, Mean $( \pm$ SEM) total activity following saline injection.,$+ P<0.05$; ++ , $P<0.01$ treatment $\times$ time interaction; ${ }^{*}, P<0.05$ treatment effect.

observed in CTX-pretreated animals following cocaine administration relative to saline-pretreated animals. A significant between-groups effect was observed following ANOVA $[F(1,13)$ $=5.137, P<0.04]$, as well as a significant group $\times$ time in- teraction $[F(14,182)-2.495, P<0.003]$. In contrast, $24 \mathrm{hr}$ following a separate CTX or saline microinjection there was no difference between the two pretreatment groups in the locomotor response to systemic saline (Fig. $3 E, F$ ). 
The Journal of Neuroscience, June 1993, 13(6) 2347
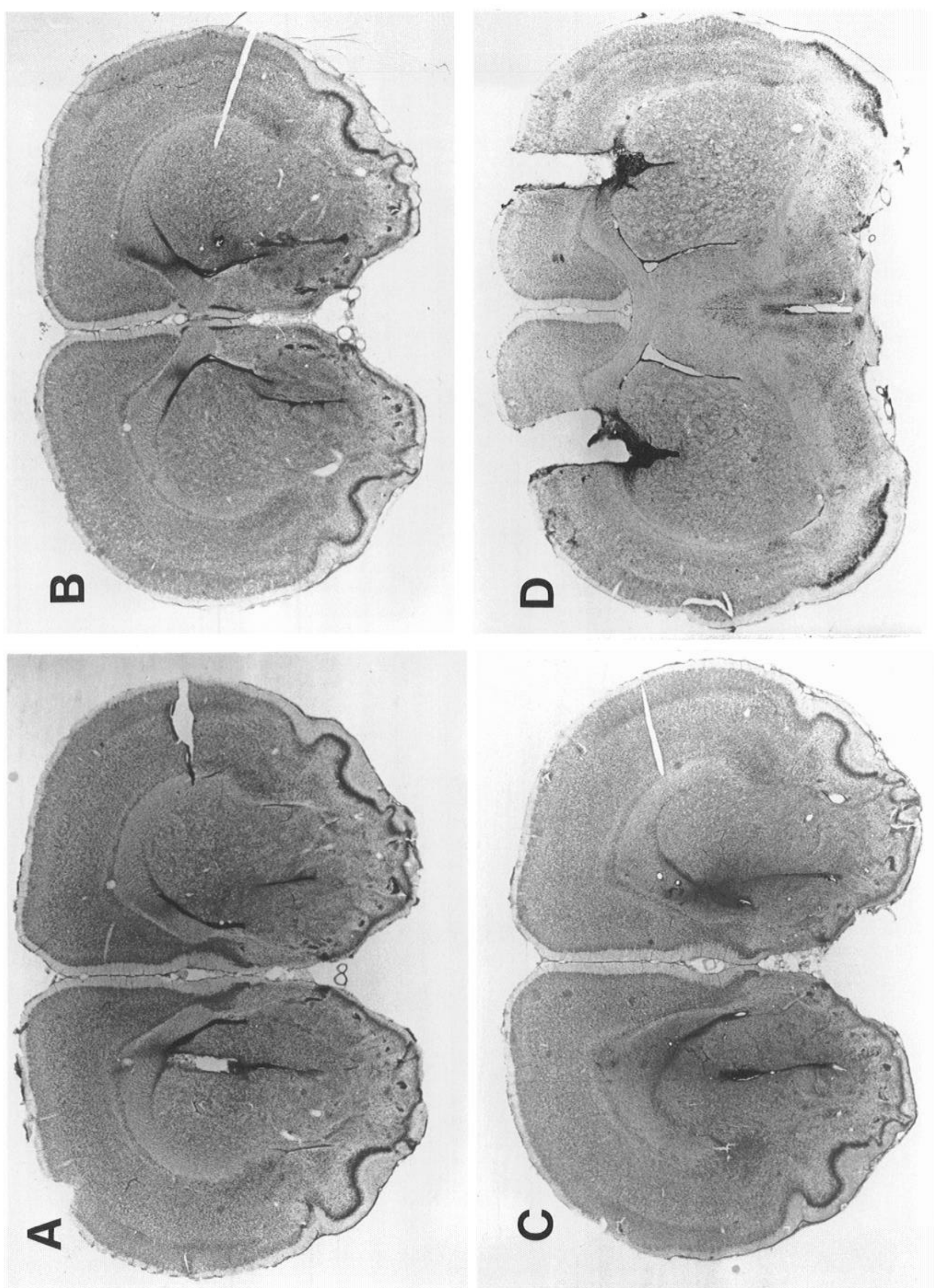

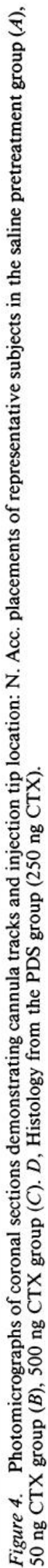




\section{Histological analysis}

Figure 4 shows photomicrographs of representative animals that had received one microinfusion of CTX or saline. There was no obvious cellular damage or toxicity observed beyond what one would normally expect as a result of brain microinjection.

\section{Discussion}

Manipulation of the $G_{s}$ protein-mediated second messenger system via intra-accumbens infusion of CTX resulted in long-lasting motor activation. This result suggests that alterations in this system have long-term yet reversible effects on behavior. The present findings demonstrate the prolonged effect of CTX on locomotor activity following a single infusion, which subsides 4-6 d later. Experiment I showed that this behavioral effect was dose dependent. The low dose of CTX $(50 \mathrm{ng})$ induced a longer delay in onset and shorter duration of hyperactivity (day 4 through day 5) and the high dose (500 ng) increased activity from day 2 through day 5 (Fig. $1 B-E$ ). In addition, activity scores of the $50 \mathrm{ng}$ group were of lower magnitude and of shorter within-session duration than those induced by the $500 \mathrm{ng}$ dose (Fig. 1D).

It was noted that several animals in the $500 \mathrm{ng}$ dose group had occasional seizures in the days following CTX infusion. It may be that prolonged upregulation of the cAMP effector system within the N. Acc. can lead to seizures. Seizures were never observed in the $50 \mathrm{ng}$ or the $250 \mathrm{ng}$ groups. For the most part, informal observation of the animals indicated that stimulated motor behavior resembled amphetamine-like behavioral patterns; animals showed high levels of sniffing locomotion and rearing.

It is unlikely that either the motor-activating effect or the seizures were caused by nonspecific toxic effects of the compound. The histological profile of rats having received one injection of saline was indistinguishable from those in the CTXtreated groups. Further, it should be noted that the doses found to be effective in these experiments were often several orders of magnitude lower than those used for biochemical or behavioral experiments with CTX (Miller and Kelly, 1975; Fujita et al., 1985; Kelly et al., 1987) or PTX (Fujita et al., 1985; Boyajian et al., 1989; Bickford-Wimer et al., 1990; Steketee and Kalivas, 1991; Augood and Emson, 1992).

Experiment II provides preliminary evidence that the motorstimulating properties of CTX are site dependent. In this experiment, $250 \mathrm{ng}$ infusion into $\mathrm{N}$. Acc. resulted in enhanced activity 2-3 d later, while no such effect was noted following similar treatment of the PDS. This result complements several studies that demonstrate functional heterogeneity of the striatum/accumbens complex with regard to microinjections of stimulants (Carr and White, 1987; Kelley et al., 1989; Delfs et al., 1990). Those studies and many others show that N. Acc. is the region most closely associated with drug-induced changes in locomotor activity. While CTX infusions into the dorsal striatum did not change locomotor activity further work would be needed to ascertain the behavioral effects of manipulation of $\mathrm{G}$-proteins in other striatal regions.

CTX prevents the deactivation of $\mathrm{G}_{\mathrm{s}}$ by ADP-ribosylating its $\alpha$-subunit, thereby inhibiting GTP hydrolysis and causing increased stimulation of adenylate cyclase. It is likely that the behavioral consequences of CTX infusion into the N. Acc. result from this mechanism (although in the present studies levels of cAMP were not determined). It appears that very few investi- gations have examined the behavioral effects of CTX. As noted earlier, well before the substrate for CTX ( $G_{s}$ protein) was established it was shown that CTX infusion into the N. Acc. elicited delayed long-lasting hyperactivity (Miller and Kelly, 1975). Our present results confirm this finding and additionally show that the effect is anatomically specific and can be obtained with lower doses. Several biochemical studies support the present findings. For example, intrastriatal CTX caused a two- to threefold increase in basal cAMP accumulation $24 \mathrm{hr}$ after injection (Fujita et al., 1985; Kelly et al., 1987). It should be noted that in both those studies 4-5 $\mu \mathrm{g}$ was used, a dose that was 100 times the effective dose in the present study.

The present findings that a very low dose of CTX (10 ng) induces a potentiated response to both amphetamine and cocaine and not to saline may have important implications for understanding the neural mechanisms associated with behavioral sensitization. Behavioral sensitization is the progressively increased response to a drug following repeated exposure to the drug. In the case of psychostimulants such as amphetamine and cocaine, there is ample evidence that repeated or intermittent treatment with stimulants can cause behavioral sensitization (Post et al., 1981, 1987; Robinson and Becker, 1986; Kalivas and Weber, 1988; Stewart and Vezina, 1988). Following a single $\mathrm{N}$. Acc. injection of a dose of CTX that had no overt effects on behavior, animals were more reactive to low doses of systemic amphetamine and cocaine relative to saline pretreatment. Since the locomotor responsc to psychostimulants is dependent on dopamine release in the $N$. Acc. and in view of the fact that CTX-induced hyperactivity persists after 6-hydroxydopamine lesion of N. Acc. (Miller and Kelly, 1975), we can hypothesize that CTX confers a greater sensitivity to the postsynaptic effects of dopamine. Also in agreement with this hypothesis are the electrophysiological data showing that repeated cocaine treatment induces prolonged $D_{1}$ receptor sensitivity in the striatum (Henry and White, 1991) in the absence of changes in $D_{1}$ receptor density (Peris et al., 1990). Taken together, these data suggest that postsynaptic changes in receptor-mediated signal transduction mechanisms in the N. Acc. may mediate behavioral sensitization. Moreover, since CTX affects the G-protein associated with the $D_{1}$ receptor, it is likely that alterations in $D_{1}$ receptor $/ G_{s}$ protein coupling account for both CTX and chronic stimulant-induced sensitization.

Although postsynaptic alterations are a likely substratc for CTX-induced effects, the possibility that behavioral sensitization results from presynaptic change in dopamine function cannot be ruled out. Microinjection of CTX into the accumbens may alter phosphorylation of presynaptic membrane proteins or enzymes. For example, Santiago and Westernik (1990) reported that both cAMP agonists and cAMP-dependent protein kinase stimulation by forskolin resulted in an increase in dopamine release in the striatum of rats. Since in the present study indirect agonists were used, it is not clear through which mechanism sensitization occurs. Further investigation with selective direct agonists is necessary to determine the specificity and localization of CTX-induced sensitization in the N. Acc.

It is of interest to compare the present results with recent reports utilizing PTX microinfusion into the ventral tegmental area (Steketee and Kalivas, 1991). PTX treatment of this region resulted in a sensitized response to amphetamine and cocainc 2 weeks later. The authors propose that manipulation of the $G_{i}$ protein that mediates $D_{2}$ and $G A B A_{B}$ receptor coupling to the $\mathrm{K}^{+}$channel may be responsible for sensitization. Thus, altera- 
tions of G-proteins within both the N. Acc. and ventral tegmental area may underlie behavioral sensitization to stimulants. In fact, there is much biochemical evidence to suggest that chronic treatment with either stimulants or morphine induces changes in G-proteins and upregulates the cAMP system (Johnson and Fleming, 1989; Nestler et al., 1990; De Vries et al., 1991; Terwilliger et al., 1991).

It is interesting that in the group treated with $50 \mathrm{ng}$ of CTX the heightened activity was only seen during levels of high arousal, that is, during the initial part of the session. Both CTX-and saline-treated rats eventually habituated to the test apparatus. In other words, there seems to be an interaction between the neural changes induced by CTX pretreatment and other stimuli that may induce normal dopamine release, such as change in environment or handling. Other experiments would be required to test this hypothesis and to investigate whether reactivity to reward-related stimuli might also be changed.

In addition to their relevance to drug abuse, these findings may also bear relevance to neural mechanisms underlying mania. Recent clinical studies have demonstrated a hyperfunction of G-proteins in manic patients (Schreiber et al., 1991), implying that altered G-protein activity may correspond to the manic state. In that study, lithium was found to restore normal G-protein function. A number of models have in fact implicated altered second messenger mechanisms in manic-depressive illness and in the therapeutic effects of lithium (Berridge, 1985; Avissar et al., 1988; Baraban et al., 1989; Manji, 1992). Since another major theory of mania implicates dopamine dysfunction, perhaps in the N. Acc. (Post, 1980), the present findings may have potential as an animal model of mania.

In summary, alterations in the G-protein-second messenger system within the $\mathrm{N}$. Acc. induce changes in motor arousal and reactivity to psychostimulants. Further investigation is necessary to determine both the neurochemical and behavioral specificity of this effect.

\section{References}

Augood SJ, Emson PC (1992) Pertussis toxin administration increases the expression of proneurotensin and preproenkephalin A mRNAs in rat striatum. Neuroscience 47:317-324.

Avissar S, Schreiber G, Danon A, Belmaker RH (1988) Lithium inhibits adrenergic and cholinergic increases in GTP binding in rat cortex. Nature 331:440-442.

Baraban JM, Worley PF, Snyder SH (1989) Second messenger systems and psychoactive drug action: focus on the phosphoinositide system and lithium. Am J Psychiatry 146:1251-1260.

Berridge M (1985) The molecular basis of communication within the cell. In: The molecules of life, pp 96-106. New York: Freeman.

Bickford-Wimer P, Kim M, Boyajian C, Cooper DMF, Freedman R (1990) Effects of pertussis toxin on caudate neuron electrophysiology: studies with dopamine D1 and D2 agonists. Brain Res 533:263-267.

Boyajian CL, Bickford-Wimer P, Kim MB, Freedman R, Cooper DMF (1989) Pertussis toxin lesioning of the nucleus caudate-putamen attenuates adenylate cyclase inhibition and alters neuronal electrophysiological activity. Brain Res 495:66-74.

Bruning JL, Kintz BL (1987) Computational handbook of statistics. Glenview, IL: Scott, Foresman.

Carr GD, White N (1987) Effects of systemic and intracranial amphetamine injections on behavior in the open field: a detailed analysis. Pharmacol Biochem Behav 27:113-122.

Delfs JM, Schreiber L, Kelley AE (1990) Microinjection of cocaine into the nucleus accumbens elicits locomotor activation in the rat. J Neurosci 10:303-310.

De Vries TJ, Van Vliet BJ, Hogenboom F, Wardeh G, Van der Laan JW, Mulder AH, Schoffelmeer ANM (1991) Effect of chronic prenatal morphine treatment on $\mu$-opioid receptor-regulated adenylate cyclase activity and neurotransmitter release in rat brain slices. Eur J Pharmacol 208:97-104.

Fibiger HC, Phillips AG (1986) Reward motivation cognition: psychobiology of mesotelencephalic dopamine systems. In: Handbook of physiology: the nervous system (Mountcastle VB, Bloom FE, Geiger SR, eds), pp 647-675. Bethesda, MD: American Physiological Society.

Fujita N, Nakahiro M, Fukuchi I, Saito K, Yoshida H (1985) Effects of pertussis toxin on D2-dopamine receptor in rat striatum: evidence for coupling of $\mathrm{Ni}$ regulatory protein with D2-receptor. Brain Res 333:231-236.

Gill DM, Meren R (1978) ADP-ribosylation of membrane proteins catalyzed by cholera toxin: basis of the activation of adenylate cyclase. Proc Natl Acad Sci USA 75:3050-3054.

Henry DJ, White FJ (1991) Repeated cocaine administration causes persistent enhancement of D1 dopamine receptor sensitivity within the rat nucleus accumbens. J Pharmacol Exp Ther 258:882-890.

Johnson SM, Fleming WW (1989) Mechanisms of cellular adaptive sensitivity changes: applications to opioid tolerance and dependence. Pharmacol Rev 41:435-488.

Kalivas PW, Weber B (1988) Amphetamine injection into the ventral mesencephalon sensitizes rats to peripheral amphetamine and cocaine. J Pharmacol Exp Ther 245:1095-1102.

Kelley AE, Gauthier AM, Lang CG (1989) Amphetamine microinjections into distinct striatal subregions cause dissociable effects on motor and ingestive behavior. Behav Brain Res 35:27-39.

Kelly E, Willcucks AL, Nahorski SR (1987) Neurochemical and behavioural evidence that dopamine D-2 receptors in striatum couple to the Ni regulatory protein and inhibition of cyclic AMP accumulation. Naunyn Schmiedebergs Arch Pharmacol 335:618-623.

Koob GF, Bloom FE (1988) Cellular and molecular mechanisms of drug dependence. Science 242:715-723.

Manji HK (1992) G proteins: implications for psychiatry. Am J Psychiatry 149:746-760.

Miller RJ, Kelly PH (1975) Dopamine-like effects of cholera toxin in the central nervous system. Nature 255:163-166.

Murayama T, Ui M (1983) Loss of the inhibitory function of the guanine nucleotide regulatory component of adenylate cyclase due to its ribosylation by islet activating protein pertussis toxin in adipocyte membranes. J Biol Chem 258:3319-3326.

Nestler EJ, Terwilliger RZ, Walker JR, Sevarino KA, Duman RS (1990) Chronic cocaine treatment decreases levels of the $G$ protein subunits Gi $\alpha$ and Goo in discrete regions of rat brain. J Neurochem 55:10791082.

Olianas MC, Onali P (1987) Pertussis toxin attenuates D2 inhibition and enhances D1 stimulation of adenylate cyclase by dopamine in rat striatum. J Neurochem 48:1443-1447.

Pellegrino LJ, Cushman AJ (1967) A stereotaxic atlas of the rat brain New York: Appleton-Century-Crofts.

Peris J, Boyson SJ, Cass WA, Curella P, Dwoskin LP, Larson G, Lin LH, Yasuda RP, Zahniser NR (1990) Persistence of neurochemical changes in dopamine systems after repeated cocaine administration. J Pharmacol Exp Ther 253:38-44.

Pijnenburg AJJ, Honig WMM, Van der Heyden JAM, Van Rossum JM (1976) Effects of chemical stimulation of the mesolimbic dopamine system upon locomotor activity. Eur J Pharmacol 35:45-58.

Post RM (1980) Biochemical theories of mania. In: Mania, an evolving concept (Belmaker RH, van Praag HM, eds), pp 217-265. New York: Spectrum.

Post RM, Lockfeld A, Squillace KM, Contel NR (1981) Drug-environment interaction: context dependency of cocaine-induced behavioral sensitization. Life Sci 28:755-760.

Post RM, Weiss SRB, Pert A, Uhde TW (1987) Chronic cocaine administration: sensitization and kindling effects. In: Cocaine: clinical and biobehavioral aspects (Fisher S, Raskin A, Uhlenhuth EH, eds), pp 109-173. New York: Oxford UP.

Roberts DCS, Koob GF, Klonoff P, Fibiger HC (1980) Extinction and recovery of cocaine self-administration following 6-hydroxydopamine lesions of the nucleus accumbens. Pharmacol Biochem Behav 12: 781-787.

Robinson TE, Becker JB (1986) Enduring changes in brain and behavior produced by chronic amphetamine administration: a review and evaluation of animal models of amphetamine psychosis. Brain Res Rev 11:157-198.

Santiago M, Westernik BHC (1990) Role of adenylate cyclase in the 
modulation of the release of dopamine: a microdialysis study in the striatum of the rat. J Neurochem 55:169-174.

Schreiber G, Avissar S, Danon A, Belmaker RH (1991) Hyperfunctional $\mathrm{G}$ proteins in mononuclear leukocytes of patients with mania. Biol Psychiatry 29:273-280.

Steketee JD, Kalivas PW (1991) Sensitization to psychostimulants and stress after injection of pertussis toxin into the A10 dopamine region. J Pharmacol Exp Ther 259:916-924.

Stewart J, Vezina P (1988) Conditioning and behavioral sensitization. In: Sensitization in the nervous system (Kalivas PW, Barnes CD, eds), pp 207-224. Caldwell, NJ: Telford.
Stoof JC, Kebabian JW (1981) Opposing roles for D-1 and D-2 dopaminc rcceptors in efflux of cyclic AMP from rat neostriatum. Nature 294:366-368.

Terwilliger RZ, Beitner-Johnson D, Sevarino KA, Crain SM, Nestler EJ (1991) A general role for adaptations in G-proteins and the cyclic AMP system in mediating the chronic actions of morphine and cocaine on neuronal function. Brain Res 548:100-110.

Worley PF, Baraban JM, De Souza EB, Snyder SH (1986) Mapping second messenger systems in the brain: differential localizations of adenylate cyclase and protein kinase C. Proc Natl Acad Sci USA 83: $4053-4057$ 